\title{
Comparative Analysis of Water Quality Indices and Their Relationship with Anthropogenic Activities. Case Study: Bogotá River
}

\section{Wilfredo Marimon ( $\nabla$ wmarimon@ucatolica.edu.co)}

Universidad Católica de Colombia: Universidad Catolica de Colombia

Nathalie Toussaint Jimenez

Universidad Católica de Colombia: Universidad Catolica de Colombia

Carlos Jiménez

Universidad Católica de Colombia: Universidad Catolica de Colombia

John Chavarro

Pontificia Universidad Javeriana

Efraín Domínguez

Pontificia Universidad Javeriana

\section{Research Article}

Keywords: Bogotá River, Water quality index, water pollution, spatial and temporal evaluation

Posted Date: May 21st, 2021

DOI: https://doi.org/10.21203/rs.3.rs-471745/v1

License: (c) (i) This work is licensed under a Creative Commons Attribution 4.0 International License. Read Full License 

COMPARATIVE ANALYSIS OF WATER QUALITY INDICES AND THEIR

\title{
RELATIONSHIP WITH ANTHROPOGENIC ACTIVITIES. CASE STUDY: BOGOTÁ RIVER
}

\author{
Wilfredo Marimón-Bolívarr ${ }^{1,2}$, Nathalie Toussaint Jimenez², Carlos Jiménez², John Chavarro², Efraín
} Domínguez ${ }^{1}$.

1. Pontificia Universidad Javeriana, Faculty of Environmental and Rural Studies, Department of Ecology and Territory. Bogotá, Colombia.

2. Research Group in Engineering for Sustainability - GRIIS, Faculty of Engineering, Universidad Católica de Colombia

3. Research Group on Dynamics of GeoAgroAmbiental Systems - DSGAA, Center for Research in GeoAgroAgroAmbiental Sciences and Resources - CENIGAA.

\section{ABSTRACT}

The Water Quality Index is the numerical value that qualifies in categories, the water quality of a surface stream, based on the measurements obtained for a set of physicochemical and microbiological parameters registered in a water quality monitoring network. This indicator allows knowing the physical-chemical and microbiological quality conditions of a body of water and identifies contamination problems at a certain point. In the present study, the water quality was studied in 43 stations located in the Bogota river, considering different methodologies for calculating quality indices such as NSF, Oregon, IDEAM, Prati, and diffuse logic to establish the differences, advantages, and disadvantages of each method. Similarly, a correlation analysis was carried out between the parameters, and the land uses in the basin. The results indicated that all the indices showed regular or poor water quality for more than $80 \%$ of the stations for the temporal window studied. However, the methodology used in Colombia (ICA water quality index, in Spanish) has eclipsing problems in most of the evaluation points since where the water quality 
26 qualifies as good, other indices such as the fuzzy logic show a degree of contamination by any of

27 the parameters mainly manganese or total suspended solids.

28 Keywords: Bogotá River, Water quality index, water pollution, spatial and temporal evaluation.

29

30

31

32

33

34

35

\section{INTRODUCTION}

Water is a development engine for communities, so knowledge about this resource, distribution, and pressure on quantity and quality constitutes the support for territorial planning and decisionmaking (Fu et al., 2020). Likewise, social dynamics and population growth lead to increased use, alterations to natural conditions, and effects on water quality that must be evaluated to define comprehensive strategies for the conservation of water systems and disaster prevention (Mester et al., 2020; Walsh and Milon, 2016).

One way to assess these pressures on water quality is to apply water quality indices. Water Quality Index (WQI) is a simple tool or method to evaluate and categorize the water resource quality and compare the state of different water bodies in different places and at other times (GradillaHernández et al., 2020; Kothari et al., 2021). This tool makes it possible to qualify the water quality as "good" or "bad", as well as give indications on the environmental effects from the measured parameters and establish which sections of rivers where the quality has changed significantly and that, if necessary, can be investigated in greater detail.

Despite their benefits, some water quality indices have complications in their uses or interpretations due to overshadowing problems where crucial information on water quality could be destroyed during the process of implementing the aggregation function, or problems of uncertainty where the variation in the selection of weights can affect the uncertainty of the evaluation and the decision making on the water body of interest (Uddin et al., 2021). 
48 The Bogotá River, which is in the Cundiboyacense highlands, from northeast to southeast of

49 Cundinamarca, is one of the water bodies of great interest in Colombia. Although it is not a 50 navigable or fast-flowing river, the Bogotá River is significant for Colombia because, in its round 51 and the surrounding areas, economic activities are developed, representing $26 \%$ of the total 52 national level (CAR, 2018). Among them, agricultural, livestock, and industrial production stand 53 out. One of the activities that generate the most significant pollution in the river is the tannery 54 sector. The basin receives wastewater from more than 100 tannery companies between the 55 municipalities of Villapizon and Chocontá. These discharges are characterized by having a high 56 load of organic chemical components and heavy metals (Suarez Escobar et al., 2012). Additionally, 57 it receives high pollutant loads from the domestic discharges of Bogotá D.C., Soacha, and other 58 municipalities that contribute about $32 \%$ of the national Gross Domestic Product (GDP), but that 59 each second discharges more than 20,000 liters per second of wastewater per second (CAR, 2006).

60 Although studies have been carried out on the determination of water quality indices of the Bogotá 61 river, these have left aside studying the problems mentioned above. Various authors have 62 formulated quality indices according to the permissible limits in the environmental standard, the 63 criteria for the specific use of water and its potential, and a reduced number of parameters with 64 significance that generate information on the change in water quality and its impact (Lozada et al., 65 2009). Díaz et al. (Díaz-Casallas et al., 2019) used the information from 29 monitoring stations for 66 the period 2008-2017 with records for five parameters (Dissolved oxygen, total suspended solids, 67 chemical oxygen demand, Electrical conductivity, and $\mathrm{pH}$ ). In the Castro et al. report (Castro 68 Fernández et al., 2015), information for 2008 - 2015 was collected for the same five parameters 69 listed above. However, when they were calculating the WQI, importance weights were given 70 equally to the five parameters, which goes against the recommendations for most approaches to 
71 calculating water quality indices where the weight of dissolved oxygen must be greater than the

72 total suspended solids or $\mathrm{pH}$ due to its importance in the degradation of organic matter and other

73 processes. Additionally, the existing correlations between the parameters found, the relationship

74 of the calculated indices with the land uses were not studied, nor did they discuss in profound the

75 possible implications of the calculation methodologies on the index, such as the aggregation

76 function.

77 For this reason, the present study aims to evaluate the water quality index on 43 stations on the

78 Bogotá River, considering different approaches, using 12 physicochemical parameters, assessing

79 the effect of the aggregation function used, the correlations between the physicochemical

80 parameters/land use, and a comparative analysis between different models of water quality index

81 for its application as a water resource management tool.

\section{2. MATERIALS AND METHODS}

83

84

\subsection{Study area}

The study area is covered of the Bogotá river basin, located in the department of Cundinamarca, where its natural system is made up of various bodies of water (rivers, streams, lagoons, reservoirs, among others) represented in nineteen (19) sub-basins that reach a total area of $6000 \mathrm{~km}^{2}$. The course of the river Bogotá is born at an altitude of 3300 meters above sea level in the municipality of Villapinzón. The upper part of the basin goes from this source to the urban area of the capital with a length of the river of $165 \mathrm{~km}$; the middle part goes up to the following $90 \mathrm{~km}$ to the Salto del Tequendama and the lower part that includes $55 \mathrm{~km}$ of the river to flow into the Magdalena river at 280 meters above sea level in the municipality of Girardot (Figure 1). As the main characteristics of this basin, the maximum water contribution is provided by precipitation through 
93 a bimodal behavior per year with values of $2200 \mathrm{~mm}$ per year and at least $400 \mathrm{~mm}$ per year and a

94 range temperature between 6 and $30^{\circ} \mathrm{C}$. The demand for this stream is given for agricultural,

95 livestock, and industrial services, so that along its route, it receives water from rivers that cross

96 large, populated centers, such as Bogotá, which leads to an increase in the polluting loads to the

97 current principal.

98

99

100

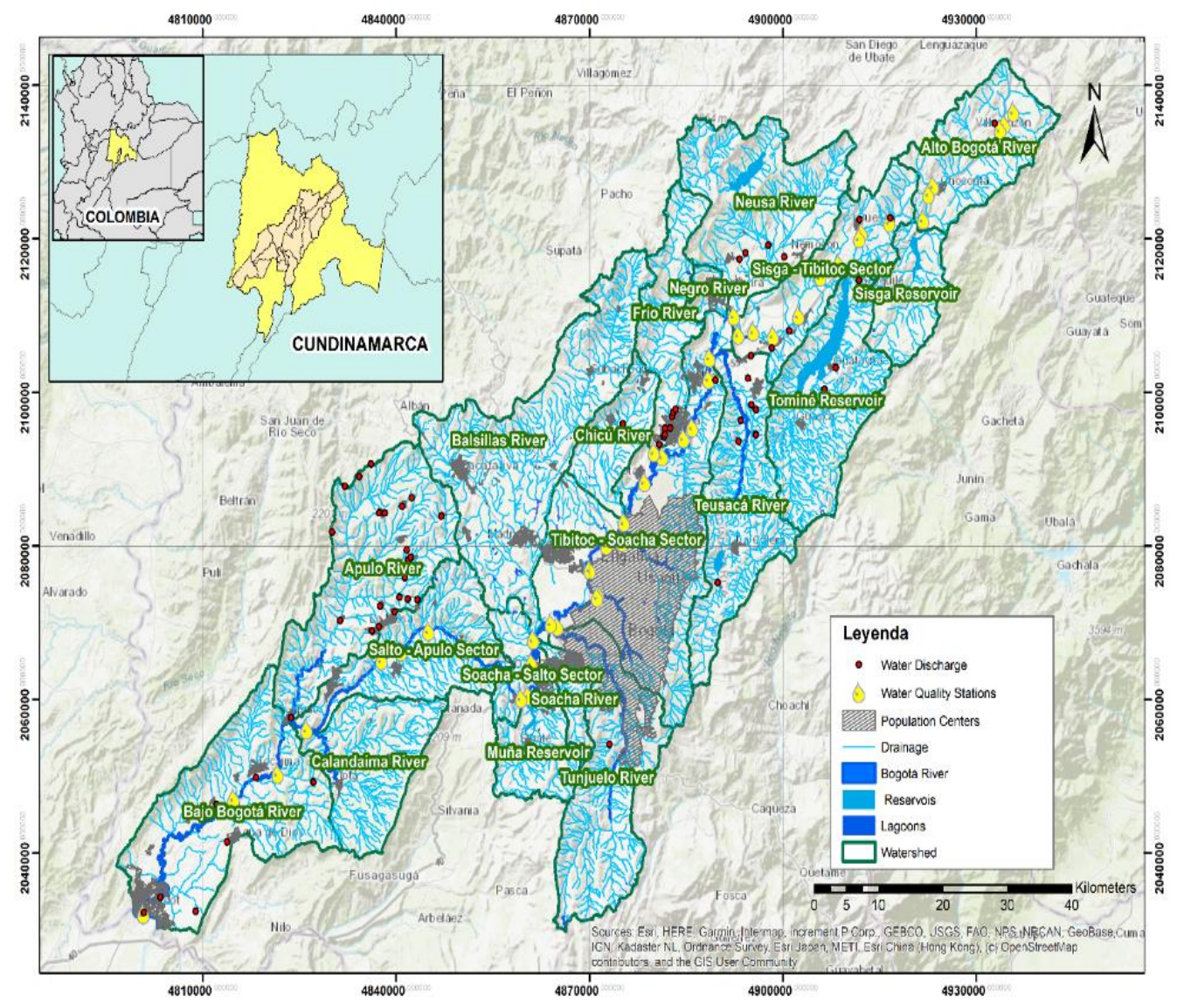

Figure 1. Study Area, Bogotá river basin.

\subsection{Data collection}

Thirty-six (36) water quality parameters were analyzed during the monitoring campaigns carried out from 2013 to 2019 in two seasons (dry and wet season). The physicochemical parameters studied include $\mathrm{pH}$, electric conductivity (EC), dissolved oxygen (DO), biochemical oxygen 
104 demand (BOD5), chemical oxygen demand (COD), turbidity, solids content (total suspended solids 105 (TSS) and total solids (ST), alkalinity, total hardness, chlorides (Cl), sulfates $\left(\mathrm{SO}_{4}\right)$, total 106 phosphorus $(\mathrm{TP})$, total nitrogen $(\mathrm{TN})$, ammonium $\left(\mathrm{NH}_{4}\right)$, nitrates $\left(\mathrm{NO}_{3}\right)$, nitrites $\left(\mathrm{NO}_{2}\right)$, total 107 Coliforms, Escherichia Coli, Al, B, Cd, Ca, Co, Cr, Fe, Mg, Mn, Hg, Ni, Ag, Pb, Se, Na, and 108 temperature. From these 36 parameters, twenty-nine (29) were selected (Supplementary material 109 1)0020that had a place within the equations for calculating the quality indices to be determined, 110 the data collected were reported in the supplementary material.

111 Also, a collection of information was realized on the databases used for the development of the 112 watershed management plans (POMCA in Spanish), which highlights crucial data on the use and 113 exploitation of the natural resources in the area included in the basin, each of these data was 114 analyzed and processed using ArcGis and summarized in detailed maps in the supplementary 115 material. In this information, those layers were identified where the conflict over water resources 116 use is the connection point with the possible causes of contamination in the riverbed. Similarly,

117 the catchment points, discharges, and the main population centers were taken into account to 118 identify the critical points of pollutant loads and their behavior along the river.

\subsection{Correlation study}

120 Pearson, Spearman, and Kendall's correlation coefficients were used to calculate the degree of 121 association between the water quality variables, where there will be a force of proportion that is 122 measured in a degree from 0 to 1 and a direction already be it positive or negative. 
124 Water quality indices were proposed to evaluate the degree of contamination and the main 125 riverbed's general quality in the basin. The indexes provide a simple, objective, and rapid method 126 that allows the integration of the essential parameters to quantify the degree of alteration of the 127 water resource's natural qualities. The analysis was performed by calculating quality indices that 128 differ in the aggregation function and evaluating the parameters.

129 2.4.1. Prati implicit contamination index. (IPI)

130 Prati, in 1971, established an index in which the parameters were transformed into pollution levels 131 through mathematical expressions, considering the polluting capacity of the indicators (Prati et al., 132 1971), (Abbasi and Abbasi, 2012). The index is defined as a weighted average between 13 133 parameters or subscripts:

$$
I P I=\frac{1}{13} \sum_{i=1}^{13} I_{i}
$$

135 Where $I_{\mathrm{i}}$, corresponds to the sub-index of each parameter.

\section{2.4.2. Sanitation Foundation Water Quality Index (NSF-WQI)}

137 This index was developed in 1970 by the National Health Foundation of the United States by 138 selecting parameters utilizing the Delphi technique, where qualification of nine variables of 139 importance that a source of the catchment for human consumption was made. It also had two toxic 140 parameters (pesticides and toxic compounds) (Uddin et al., 2021). We applied an aggregation 141 function based on a weighted arithmetic average to calculate the NSF-WQI index.

$$
N S F-W Q I=\sum_{i=1}^{n} S I_{i} W_{i}
$$


143 Where $S I_{i}$, corresponds to the sub-index of the parameter that arises from the parameter curves and $144 W_{i}$, is the weighting factor for the sub-index.

145 2.4.3. Dinuis second index (IWQ).

146 This index is made up of nine chemical and two microbiological variables (coliforms toles and $E$ -

147 coli), which, unlike the previous indices, the added value is obtained through a weighted geometric

148 average and whose use is oriented for management as a source of the capture of water for 149 consumption, agriculture, fishing, and aquatic life, industry, and recreation (Castro et al., 2014).

150 The following formula defines the second index of Dinius:

151

$$
I W Q=\prod_{i=1}^{n} I_{i}^{W_{i}}
$$

152 Where $I Q W$, is the water quality index, $I_{i}$ corresponds to the sub-index of the parameter that arises 153 from the parameter curves and $W_{i}$, is the weighting factor for the sub-index.

154 2.4.4. Aquatic toxicity index (ATI)

155 This index includes an additive aggregation of a modified unweighted average, which also 156 transforms the parameters that affect the aquatic ecosystem. Among the parameters, the presence 157 of heavy metals such as copper, chromium, lead, and nickel stands out. It is developed by:

$$
A T I=\frac{1}{100}\left(\frac{1}{n} \sum_{i=1}^{n} q_{i}\right)^{2}
$$

159 Where $n$ is the number of parameters and $q_{i}$ is the characteristic function of the indicator 
161 This index analyzes a group of defined water quality variables. It produces a general value through

162 an aggregate by the square root of the unweighted harmonic average, where they involve a 163 transformation of the parameter through a non-linear regression visualized in the curves, 164 describing the water quality for rivers and streams (Castro et al., 2014). The calculation of the 165 index is given by:

$$
O W Q I=\sqrt{\frac{n}{\sum_{i=1}^{n} \frac{1}{S I^{2}}}}
$$

\subsubsection{Water Quality Index (ICA)}

During the National Water Study of Colombia (IDEAM, 2010) and in search of establishing a 169 simple method for determining the global quality of a water source mainly for human consumption, 170 IDEAM developed a simplified index based on the UWQI (Universal Water Quality) methodology 171 which is formulated with parameters that reflect the various sources of organic pollution and the 172 environmental response that the body of water may have:

$$
I C A=\sum_{i=1}^{n} I_{i} W_{i}
$$

\section{2.4.7. ICAGA'S FUZZY WQ}

175 Six fuzzy sets were used to define the membership functions in terms of input indicators for each 176 parameter. The elements of the universe of discourse $(\mathrm{X})$ were linked to the interval $[0,1]$ by this 177 membership function. The fuzzy set $\mathrm{A} \subset \mathrm{X}$ is denoted by:

$$
A=\{x \in X\}, 0 \leq \mu_{A}(X)=1
$$

179 Donde $\mu_{A}(X)$ is a degree of membership between 0 and 1. 
180 For the parameters, the trapezoidal shape was used for the membership functions. A linguistic term

181 introduced each set in X. The terms used for fuzzy sets were very low (VL), low (L), moderate

$182(\mathrm{M})$, high $(\mathrm{H})$, very high $(\mathrm{VH})$, and extremely high $(\mathrm{EH})$. The fuzzy sets were created using the 183 trapezoidal approach. The rules cover different possible modes in the SWQ applying the 184 parameters. For this research, more than 300 rules were created based on expert knowledge. The 185 following are examples of the rules that met the expert knowledge obtained from (Camara et al., 186 2020; Srinivas and Singh, 2018; Zou et al., 2006):

- if the DO is "low" and the BOD is "very low", then the water quality is "moderate."

- if the pH is "low" and the temperature is "moderate", then the water is "moderate."

- if the fecal coliform is "very low" and the total coliform is "very low", then the water quality is "excellent."

The evaluation of the rules was performed where the composition of the result of a fuzzy if-then rule. In this process, the lowest class of any selected parameters becomes the fuzzy index class for that rule. The lowest class and corresponding value of the membership function for any selected parameters become the class of the rule's fuzzy index. In this step, the applicable fuzzy rules for the given data are identified. Next, an aggregation of rule outputs where the maximum value of the fuzzy index has the same class is considered among the available applicable rules. Finally, the results of all applicable rules are grouped into a single fuzzy distribution by fuzzy joining the applicable rules to convert the fuzzified output to the sharp value. All the rules and calculations were made using the Fuzzy Logic Toolbox in Python 3.8.

\section{RESULTS AND DISCUSSION}


From the water quality data obtained from the information collection, the respective organization, tabulation, and graphing was carried out employing boxes and whiskers of each of the twenty-nine (29) key parameters for the development of the indices to determine the behavior along the outliers in the samples (Supplementary Material 1).
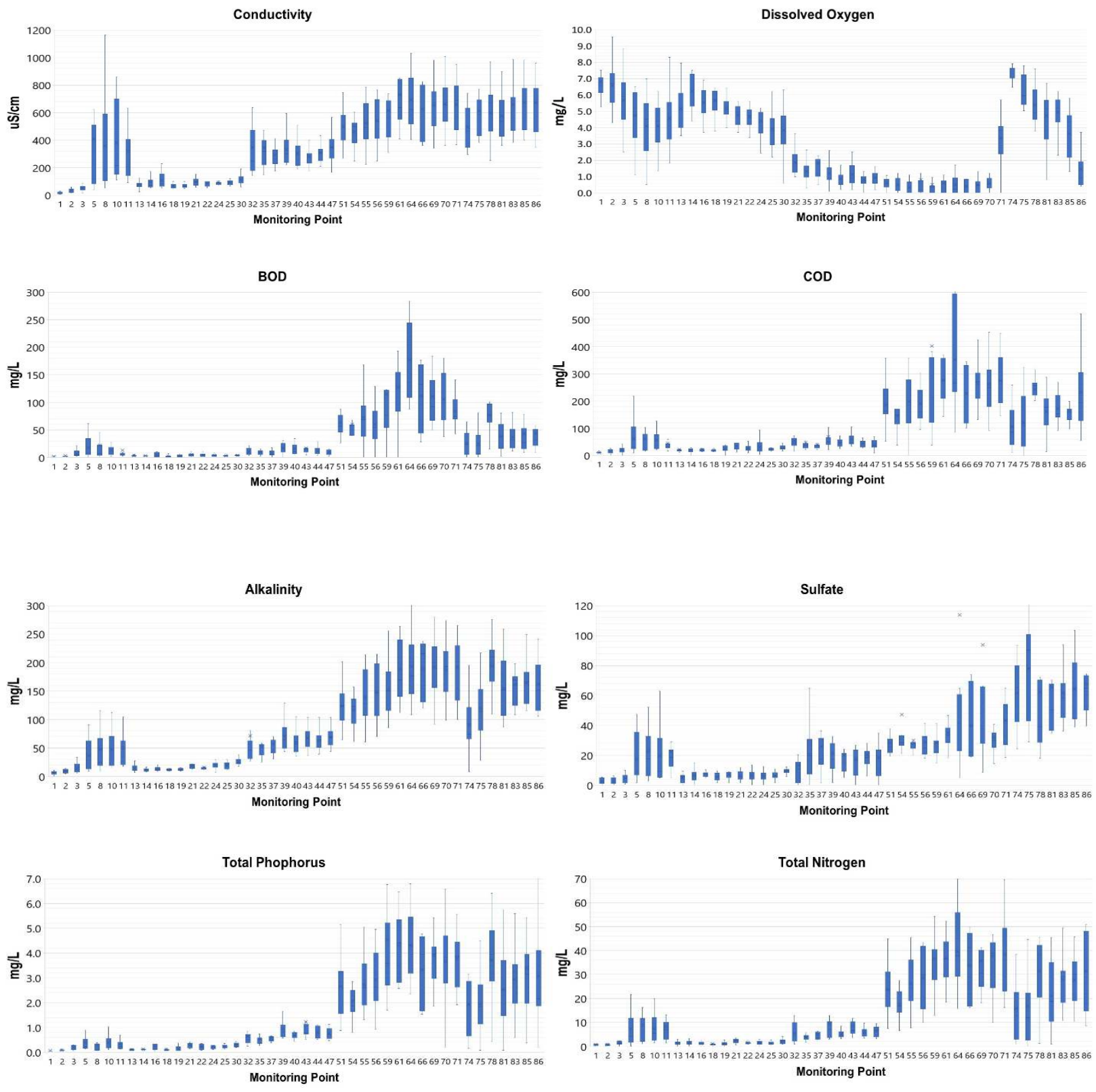

Figure 2 . The behavior of water quality along the river. 
210 When comparing the concentrations with the respective quality objective required for that section,

211 it is observed that a large part of the points does not meet these quality objectives (Figure 2). The

212 only variable that remains within the range required by the environmental authority is the $\mathrm{pH}$.

213 However, it fluctuates between 6 to $8 \mathrm{pH}$ units, where the maximum value is in the stations near

214 the river mouth.

215 A significant increase in the values in some parameters such as Electrical Conductivity (EC) and

216 Chlorides was identified along the river, while a dissolved oxygen reduction was evidenced. These

217 results are due to the anthropogenic activity in the area, which includes the tannery industry

218 (mainly in the upper and middle part of the basin) that carries out dumping of soluble substances

219 in its production process and susceptible to oxidation processes. Also, the agricultural activity has

220 adverse effects on river quality, particularly the potato crops in the area and agrochemicals,

221 fertilizers, and pesticides that reach the water body through secondary tributaries (Bautista, 2004).

222 The water body improves its quality with the discharge of water from the Sisga reservoir, causing

223 a positive effect on the self-purification capacity of the Bogotá River, but as it descends and

224 discharges from municipal treatment plants and industrial discharges are incorporated, that present

225 a high concentration of suspended solids, the calculated indices showed a deterioration in water

226 quality.

227 For dissolved oxygen, a constant decrease is shown when the municipalities' sewage discharges

228 begin. As the river slope decreases, the BOD and COD indicators increase, generating anoxic

229 conditions that significantly affect the self-purifying processes of the source. However, when

230 reaching sections where the slope's value increases (stations after the Muña reservoir), the oxygen

231 concentration gradually increases. 
232 Relate to the concentrations of phosphorus and nitrogen compounds, eutrophication problems are

233 detected mainly in the middle basin, associated with increased organic matter generated by effluent

234 discharges from the capital and agricultural runoff promoting the algae and bacteria growth.

235 Regarding the causes of bacteriological contamination in water, high concentrations of 236 cauliflowers are due to livestock activities and domestic sewage. Additionally, the presence of 237 metals such as chromium was detected due to the micro-industries of tanneries; lead, mercury, and 238 nickel from agrochemicals but with low concentration values $(<0.01 \mathrm{mg} / \mathrm{L})$. However, it was 239 possible to observe some atypical values, mainly in the parameter of total mercury, in the 240 monitoring carried out in 2017. Other of the metals detected were iron, sodium, magnesium, 241 calcium, and manganese, the latter found in high concentrations in water.

242 Finally, in the Magdalena River's vicinity, the Bogotá River has a higher concentration of 243 suspended solids and total solids, which indicates a significant increase in turbidity in the last 244 monitored stations. It is also important to emphasize that in addition to the pressure that the upper 245 and middle basin generates on the lower one, the slopes decrease, which affects the transport of 246 sediments and even the production of nutrients such as phosphorus and nitrogen, whose value is 247 higher. In this area, a large part of the lower basin pollution is caused by tourism development, 248 reaching the highest levels of pollution.

\section{3.2. Correlation}

250 The correlation matrix of the water physicochemical parameters in the study area shows the 251 correlation between different variables and the degree of correlation as a function of the Pearson, 252 Spearman, and Pearson correlation coefficient. The magnitudes of the coefficient of $0.7-1,0.5$ 2530.7 , and less than 0.5 have been classified as strong, moderate, and weak correlations, respectively. 
254 A positive correlation means that when one parameter increases, another parameter also increases

255 along with that parameter. A negative correlation means that when the value of one parameter

256 increases, the value of another parameter decreases, and its source, the characteristics are not

257 homogeneous. The analysis showed a strong positive correlation between EC and Alkalinity

258 (0.840). This strong relationship is due to metal ions like calcium carbonates in the water that

259 increase the electrical conductivity. Hardness as a parameter presents a similar relationship with

260 calcium ions and, in turn, with iron ions (Supplementary material 2).

261 Likewise, a positive correlation was found between nitrates, iron, and manganese, which supports

262 a component of inorganic contamination associated with agricultural activities in the basin.

263 Additionally, the positive correlation between biochemical oxygen demand and ammoniacal 264 nitrogen supports the fact that anoxic conditions occur in some river parts.

265 3.3. Water quality indices

266 The quality indices were calculated by year and by season to carry out the respective comparison

267 and identification of the behavior and evolution both temporally and spatially. The results were

268 reported on location maps developed in ArcGIS (Supplemental Material 3 and 4).

269 It is remarkable to observe the indices' behavior in Figure 3, where the quality of the water

270 deteriorates as the channel is traversed. A similar trend is shown between the ICA, Oregon, and

271 aquatic indices, where there is a considerable reduction in the stations located in the upper basin,

272 mainly in Villapinzón, due to the presence of tanneries in the area, extensive livestock, and the

273 presence of rotating crops. After downstream of the Villapizón, a recovery is appreciated due to

274 incorporating good quality tributary channels that support pollutants' degradation. However, the 
275 passage through the populated center's prints a gradual deterioration in water quality due to 276 discharges of domestic origin, agricultural and industrial activities (Swamee and Tyagi, 2007).

277

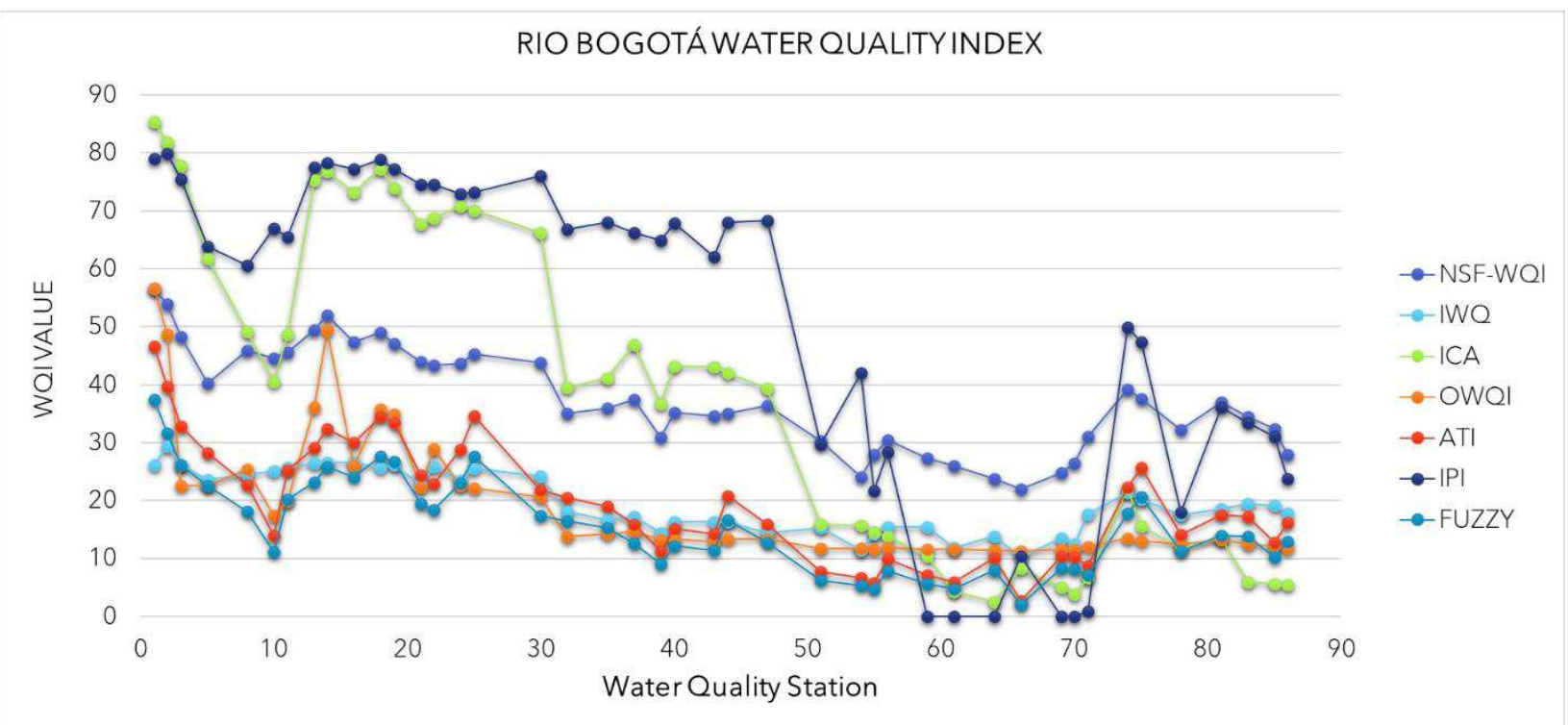

Figure 3. Comparison of water quality indices in the Bogotá River.

When comparing the results of the water quality and the calculated water quality indices, it can be established that there is a concordance since, in the discharges reported by the environmental authority, there are records of 547 domestic and 150 non-domestic discharges, which corresponds to $78.5 \%$ and $21.5 \%$ respectively (Supplementary Material 5).

Within the characterization of these non-domestic discharges, it is found that there are conductivity values greater than $10,000(\mu \mathrm{S} / \mathrm{cm})$, COD greater than $4000 \mathrm{mg} / \mathrm{L}$, and organic nitrogen above 70 $\mathrm{mg} / \mathrm{L}$, coming from cultivation activities that do not have water treatment plants or are of very low effectiveness. Additionally, there are records of several domestic discharges with a concentration of total suspended solids with values higher than $200 \mathrm{mg} / \mathrm{L}$, total nitrogen above $40 \mathrm{mg} / \mathrm{L}$, and total coliforms above 100,000 CFU/100 ml, which goes in deterioration of the surface water resource. 
290 Wastewater management plans of the basin show how treatment plant works are being prioritized

291 in the middle and/or lower part (for example, CANOAS wastewater treatment plant), which is

292 unfortunate since it is much easier to carry out treatments due to the amount of water to be treated

293 and according to the quality indices calculated, the impacts will be more significant for the

294 ecological benefit of the basin.

295 Since the source of the river in the Guacheneque moor (water quality stations 5 to 10), the quality

296 has been affected by the wastewater discharges associated with potato crops and Villapinzon

297 wastewater (Domestic and industrial). These discharges are characterized by high phosphorus

298 concentrations that tend to deteriorate the river water quality when released at a small flow of the

299 river. Although all the quality indices decrease, ICA classifies it as water with good quality, which

300 does not allow adequate management and planning of water resources.

301 On the other hand, when comparing the evaluation of each water quality index, when the Prati 302 method is implemented (which uses a weighted average), it was observed that having a parameter 303 in which there is a high value in the Manganese concentrations is you get a highly polluted water 304 quality result that. However, when making the comparison with other indices such as the NSF305 WQI, another classification of the quality of the water resource is obtained since they overshadow 306 this potential contamination due to its aggregating function, that is, the index does not accurately 307 reflect the real situation of the quality of the water.

308 The water quality index designed in Oregon has a greater sensitivity to changes in individual 309 variables, so in specific critical parameters such as total solids, it shows a greater weight on the 310 final assessment of water quality. This methodology confronts overshadowing problems leading 311 to poor decision-making by the environmental authority (Torres Vega, 2009). 
312 The opposite case is presented in the methodology proposed by IDEAM, of a weighted sum type

313 formula, it is clear to notice a significant increase in the assessment of water quality since the index

314 presents a lower sensitivity and eclipsing problems since values that do not, they have as much

315 variability as the $\mathrm{pH}$ they have the same weight as parameters that can become more critical such

316 as BOD or coliforms.

317 Unlike the other indices, the index calculated using fuzzy logic presents quality values within the

318 range of highly contaminated since it is very susceptible to obtaining adverse or low results if any

319 parameter is not within the range of good quality, being more demanding in the results. This

320 methodology showed that it is necessary to meet all the parameters quality objectives, which

321 avoids overshooting or inferior weighting in the implementation of water quality indices.

322 It can be seen how in the middle part of the basin (stations 40 to 50), where the river receives high

323 pollutant loads of domestic origin added to point and diffuse pollution associated with agricultural

324 activities, the NSF and ICA indices qualify the water quality as regular (approximately 60). This

325 is totally contrary to the classification given when applying indices with more rigorous aggregating

326 functions or that evaluate more critical parameters such as the aquatic toxicity index or the fuzzy

327 logic index.

328 Comparing our results with previous studies (Nayak et al., 2020; Oladipo et al., 2021), we observe 329 that the fuzzy logic approach reveals with greater accuracy the actual situation of the water 330 resource in the study area regardless of the rate or intensity of surface water contamination. The 331 use of indices that use a weighted average such as the NSF-WQI becomes deficient in the scenario 332 with high pollutant loads (for example, the Bogotá River basin), since its curves for calculating 333 subscripts have limitations for BOD and total solids. 
334 In this sense, the classification of water quality in the upper part of the basin shows that for the

335 indices such as NSF and ICA, it is fair or reasonable, while the quality index obtained through the

336 fuzzy logic methodology the quality is terrible given finding high concentrations of coliforms (>

$33720,000 \mathrm{CFU} / 100 \mathrm{ml})$, manganese $(>15 \mathrm{mg} / \mathrm{L})$ or lead $(>5 \mathrm{mg} / \mathrm{L})$ in measurements.

338 Finally, the results are essential for decision-making since, from the water quality classifications,

339 development policies are created or implemented for the care or use of natural resources. Similarly,

340 environmental authorities can further analyze water quality monitoring plans in order to increase

341 the frequency of measurement of the parameters that had a more significant influence on the

342 classification of water quality and thus have more tools in the issuance or evaluation of discharge

343 licenses.

\section{CONCLUSIONS}

345 Water quality is directly affected by anthropogenic activities, where the constant discharges of 346 residues produced by extensive livestock farming, the chemicals applied to crops and domestic 347 waters lead the polluting loads in the Bogotá River, which due to its low self-purifying capacity in 348 its journey and few treatment processes negatively affects the environment and surrounding 349 ecosystems.

350 Water quality indices show global results, which manage to be another alternative for the various 351 environmental control agencies, such as autonomous corporations, whose purpose seeks the 352 efficiency in decision-making concerning the protection of the water source, such as granting any 353 discharge permit or environmental evaluation and monitoring of the resource.

354 As the indices are a numerical value based on a subjective construction, they present problems 355 mainly in the definition of the functions where the transformation of each of the concentrations of 
356 the measured parameters is carried out. This happens since these functions depend to a large extent

357 on the ecosystem contexts where they were developed and based on the opinion of groups of 358 experts who analyzed the behavior of the water and the use that is to be made, causing the functions 359 to vary in the indices and not there is a universal index applicable to all the water resources present 360 on the planet. However, opting for the use of indices as a global measure is an efficient and simple 361 way that must be promoted in order to optimize the results and make them consistent with reality.

362 Each one of the characteristics of the indices proposed by various authors was identified in 363 accordance with the calculation criteria specified in each index in which they found deficiencies, 364 problems of sensitivity, rigidity, overshadowing, behavior in similar results, and subjective 365 descriptions of the quality of the Water. In accordance with the above, it is concluded that when 366 implementing an index, each of the criteria must be considered, as well as the greatest number of 367 parameters measured and applied in the mathematical expression, the uses of water and the 368 effectiveness in currents.

369 Similarly, for time-scale studies, it is better to apply indices that use unweighted harmonic average 370 or fuzzy logic in their calculation form, such as the modified Oregon index, since they are more 371 susceptible to changes and negative values in individual parameters, and thus better assess the 372 quality of the water resource in relation to the surrounding anthropogenic activities.

\section{Data availability}

374 The datasets supporting the conclusions of this article are included within the article and its 375 additional file.

\section{ACKNOWLEDGMENTS}


377 The authors thank the Corporación Autónoma Regional de Cundinamarca (CAR) for providing the data

378 used in this study.

\section{Funding}

380 Open Access funding enabled and organized by Pontificial Universidad Javeriana and Universidad Catolica

381 de Colombia.

\section{Ethics declarations}

383 Competing interests

384 The authors declare that they have no competing interests.

385 Ethics approval and consent to participate

386 Not applicable.

387 Consent for publication

388 Not applicable.

389 Contributions

390 All authors contributed to the study conception and design. Method implementation and optimization,

391 analysis, and data evaluation were performed by NT, JC and CJ. The first draft of the manuscript was

392 written by WM and ED and all authors commented on previous versions of the manuscript. All authors read 393 and approved the final submitted manuscript.

\section{Corresponding author}

395 Correspondence to Wilfredo Marimón-Bolivar. 


\section{REFERENCES}

397 Abbasi, T., Abbasi, S., 2012. Water Quality Indices, Water Quality Indices. Elsevier. $398 \quad$ https://doi.org/10.1016/C2010-0-69472-7

Bautista, J.I., 2004. Vista de Las Curtiembres del Corredor Villapinzón--Chocontá y el Río Bogotá [WWW Document]. Rev. Fac. Ciencias Económicas Investig. y Reflexión.

Camara, M., Jamil, N.R., Abdullah, A.F. Bin, Hashim, R. binti, Aliyu, A.G., 2020. Economic and efficiency based optimisation of water quality monitoring network for land use impact assessment. Sci. Total Environ. 737, 139800. https://doi.org/10.1016/j.scitotenv.2020.139800

CAR, 2018. Biodiversidad | Río Bogotá [WWW Document].

CAR, 2006. PLAN DE ORDENACIÓN Y MANEJO DE LA CUENCA HIDROGRÁFICA DEL RÍO BOGOTÁ.

Castro Fernández, M.F., Díaz Casallas, D.M., Montenegro Marín, C.E., 2015. Análisis de la Calidad del Agua del Río Bogotá Dura nte el Periodo 2008 - 2015 a Par tir de Herra mientas de Minería de Datos. Publicaciones e Investig. 9, 37. https://doi.org/10.22490/25394088.1432

Castro, M., Almeida, J., Ferrer, J., Diaz, D., 2014. Indicadores de la calidad del agua: evolución y tendencias a nivel global. Ing. Solidar. 10, 111-124. https://doi.org/10.16925/in.v9i17.811

Díaz-Casallas, D.M., Castro-Fernández, M.F., Bocos, E., Montenegro-Marin, C.E., Crespo, R.G., 2019. 2008-2017 Bogota River water quality assessment based on the water quality index. Sustain. 11, 1668. https://doi.org/10.3390/su11061668

Fu, B., Horsburgh, J.S., Jakeman, A.J., Gualtieri, C., Arnold, T., Marshall, L., Green, T.R., Quinn, 
N.W.T., Volk, M., Hunt, R.J., Vezzaro, L., Croke, B.F.W., Jakeman, J.D., Snow, V., Rashleigh, B., 2020. Modeling Water Quality in Watersheds: From Here to the Next Generation. Water Resour. Res. https://doi.org/10.1029/2020WR027721

Gradilla-Hernández, M.S., de Anda, J., Garcia-Gonzalez, A., Montes, C.Y., Barrios-Piña, H., Ruiz-Palomino, P., Díaz-Vázquez, D., 2020. Assessment of the water quality of a subtropical lake using the NSF-WQI and a newly proposed ecosystem specific water quality index. Environ. Monit. Assess. 192, 1-19. https://doi.org/10.1007/s10661-020-08265-7

Kothari, V., Vij, S., Sharma, S., Gupta, N., 2021. Correlation of various water quality parameters and water quality index of districts of Uttarakhand. Environ. Sustain. Indic. 9, 100093. https://doi.org/10.1016/j.indic.2020.100093

Lozada, P.T., Vélez, C.H.C., Patino, P., 2009. Índices de calidad de agua en fuentes superficiales utilizadas en la producción de agua para consumo humano. Una revisión crítica. Rev. Ing. Univ. Medellín 8, 3.

Mester, T., Balla, D., Szabó, G., 2020. Assessment of Groundwater Quality Changes in the Rural Environment of the Hungarian Great Plain Based on Selected Water Quality Indicators. Water. Air. Soil Pollut. 231, 1-14. https://doi.org/10.1007/s11270-020-04910-6

Nayak, J.G., Patil, L.G., Patki, V.K., 2020. Development of water quality index for Godavari River (India) based on fuzzy inference system. Groundw. Sustain. Dev. 10, 100350. https://doi.org/10.1016/j.gsd.2020.100350

Oladipo, J.O., Akinwumiju, A.S., Aboyeji, O.S., Adelodun, A.A., 2021. Comparison between fuzzy logic and water quality index methods: A case of water quality assessment in Ikare community, Southwestern Nigeria. Environ. Challenges $3, \quad 100038$. 
440

441

442

443

444

445

446

447

448

449

450

451

452

453

454

455

456

457

458

459

Prati, L., Pavanello, R., Pesarin, F., 1971. Assessment of surface water quality by a single index of pollution. Water Res. 5, 741-751. https://doi.org/10.1016/0043-1354(71)90097-2

Srinivas, R., Singh, A.P., 2018. Development of a comprehensive fuzzy based approach for evaluating sustainability and self-purifying capacity of river Ganges. ISH J. Hydraul. Eng. 24, 131-139. https://doi.org/10.1080/09715010.2017.1400407

Suarez Escobar, A.F., Garcia Ubaque, C.A., Vaca Bohorquez, M.L., 2012. Identificación y evaluación de la contaminación del agua por curtiembres en el municipio de Villapinzón. Tecnura.

Swamee, P.K., Tyagi, A., 2007. Improved Method for Aggregation of Water Quality Subindices. J. Environ. Eng. 133, 220-225. https://doi.org/10.1061/(asce)0733-9372(2007)133:2(220)

Torres Vega, F., 2009. Desarrollo y Aplicación de un Índice de Calidad de Agua para ríos en Puerto Rico.

Uddin, M.G., Nash, S., Olbert, A.I., 2021. A review of water quality index models and their use for assessing surface water quality. Ecol. Indic. 122, 107218. https://doi.org/10.1016/j.ecolind.2020.107218

Walsh, P.J., Milon, J.W., 2016. Nutrient Standards, Water Quality Indicators, and Economic Benefits from Water Quality Regulations. Environ. Resour. Econ. 64, 643-661. https://doi.org/10.1007/s10640-015-9892-2

Zou, Z.H., Yun, Y., Sun, J.N., 2006. Entropy method for determination of weight of evaluating indicators in fuzzy synthetic evaluation for water quality assessment. J. Environ. Sci. (China) 


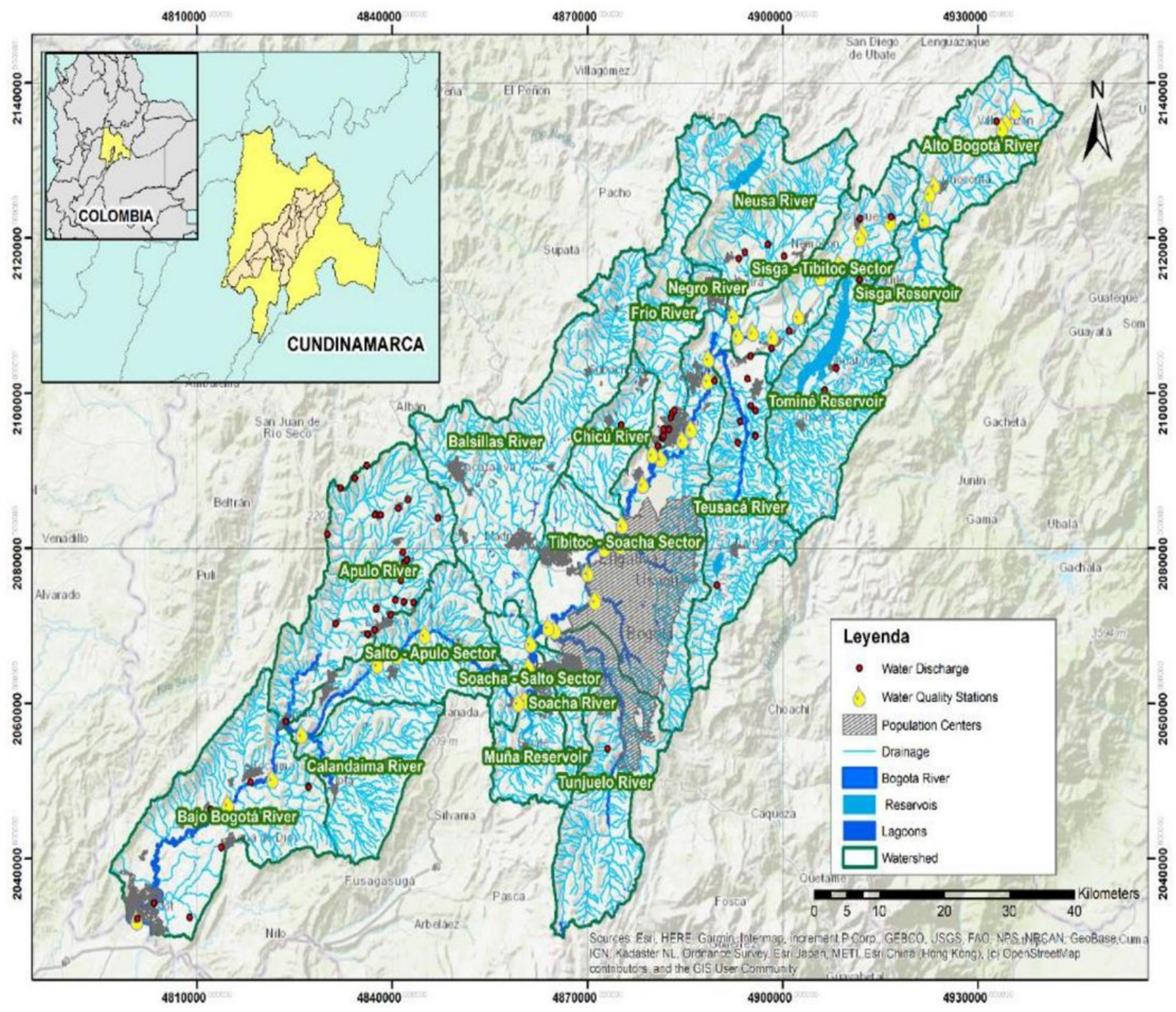

Figure 1

Study Area, Bogotá river basin. Note: The designations employed and the presentation of the material on this map do not imply the expression of any opinion whatsoever on the part of Research Square concerning the legal status of any country, territory, city or area or of its authorities, or concerning the delimitation of its frontiers or boundaries. This map has been provided by the authors. 

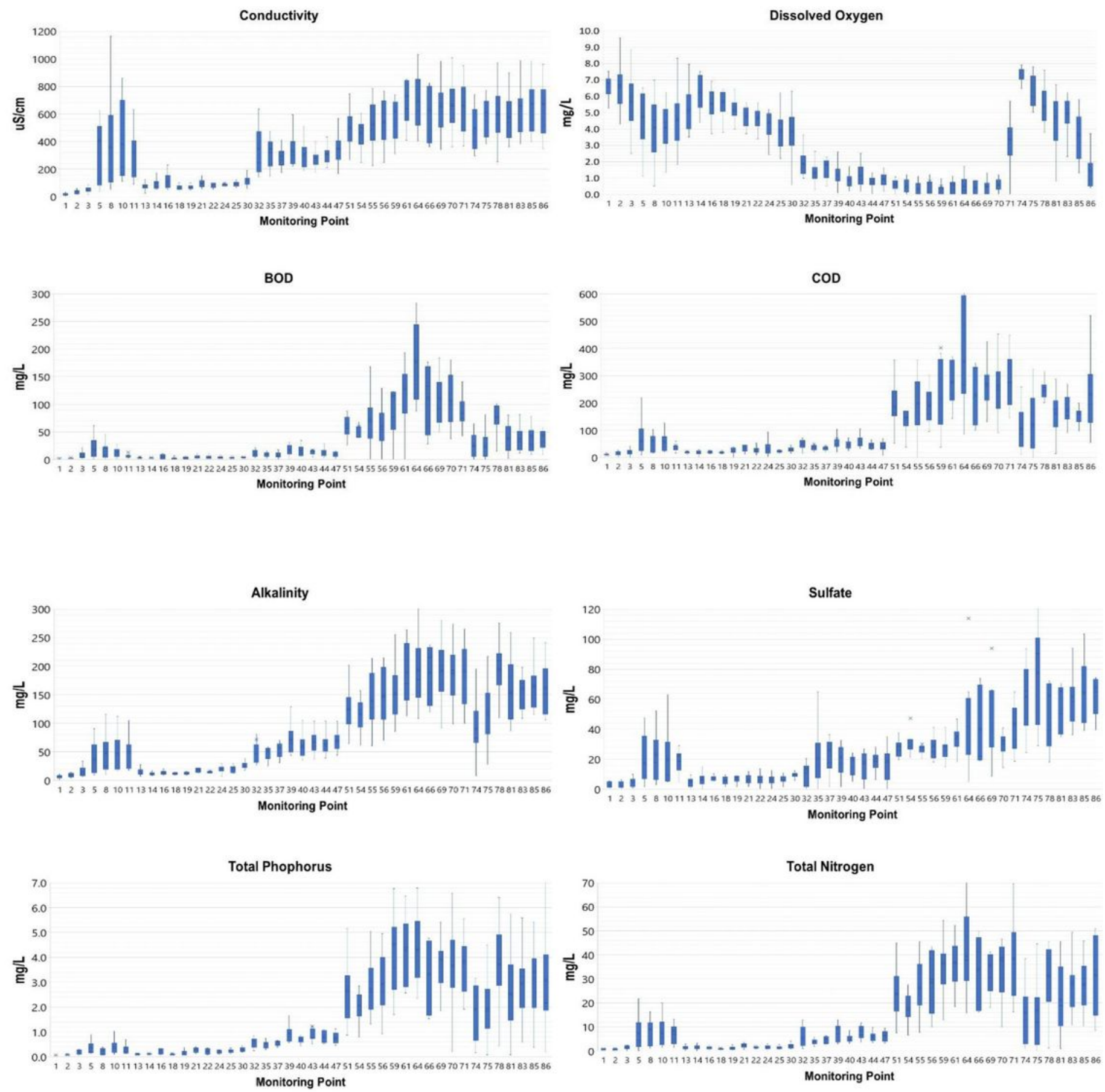

Figure 2

The behavior of water quality along the river. 


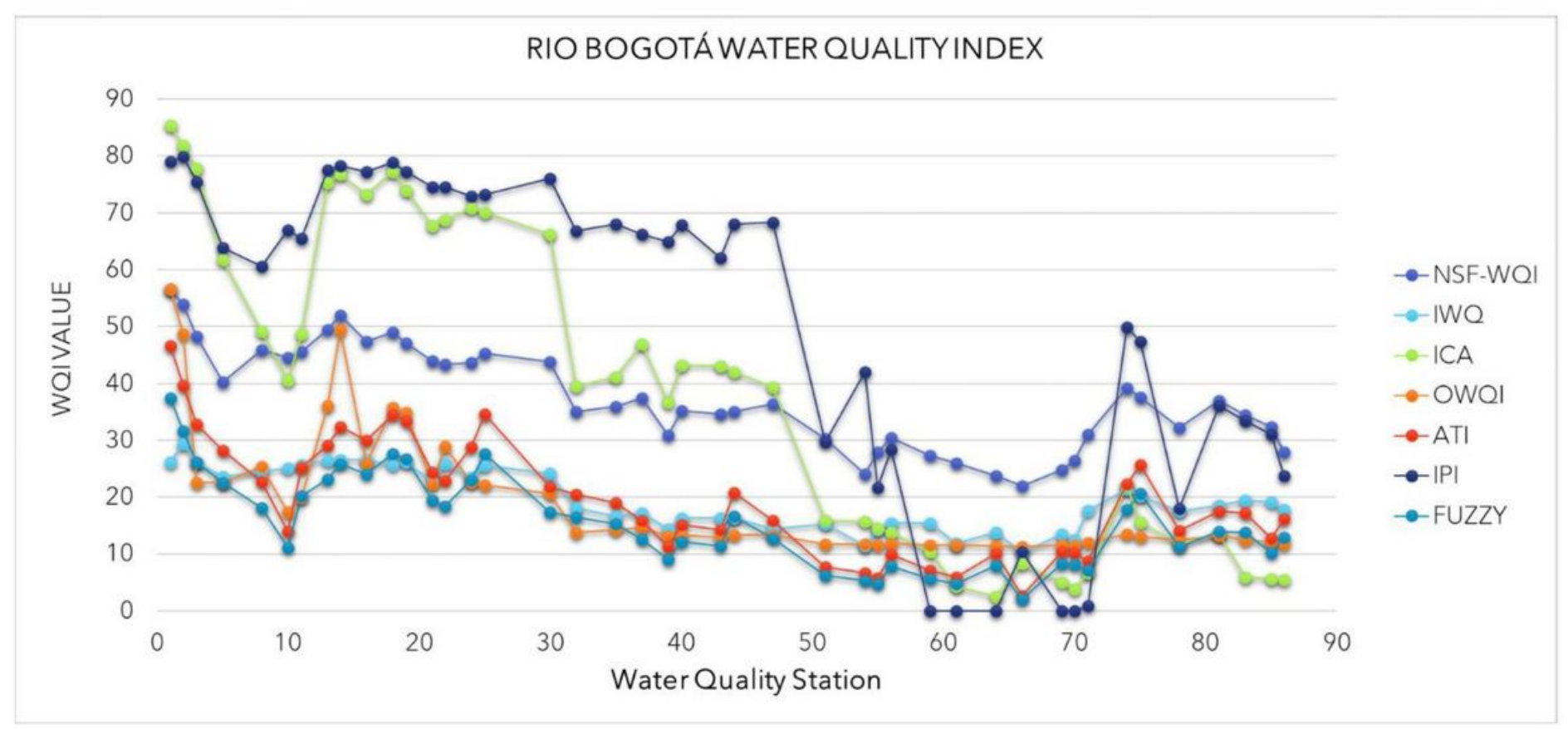

Figure 3

Comparison of water quality indices in the Bogotá River.

\section{Supplementary Files}

This is a list of supplementary files associated with this preprint. Click to download.

- SuplementaryMaterial.rar 